\title{
祁连山中段黑河上游山区地表径流水资源主要形成 区域的同位素示踪研究
}

王宁练, 张世彪, 贺建桥, 蒲健辰, 武小波, 蒋喜

冰冻圈科学国家重点实验室, 中国科学院寒区旱区环境与工程研究所, 兰州 730000

E-mail: nlwang@1zb.ac.cn

2008-04-10 收稿, 2009-07-07 接受

中国科学院创新团队国际合作伙伴计划项目(编号: CXTD-Z2005-2)、国家杰出青年科学基金项目(批准号: 40525001)、国家重点基础研究发展 计划(编号: 2005CB422003)和中国科学院知识创新工程重要方向项目(编号: KZCX2-YW-310)资助

摘要 通过对黑河干流上游祁连山区降水中 $\delta^{18} \mathrm{O}$ 随海拔高度变化的研究, 揭示出其变化 具有显著的高程效应, 高度梯度约为 $-0.18 \% / 100 \mathrm{~m}$. 利用同位素示踪技术, 并结合出山口 河水中 $\delta^{18} \mathrm{O}$, 认为出山径流主要形成于高海拔山区. 应用“ 二分量模型”，阐明了海拔 $3600 \mathrm{~m}$ 以上的高山冰雪冻土带是黑河山区流域的主要产流区, 产流量占出山径流量的 $80.2 \%$.

关键词

稳定同位素示踪

黑河

径流

祁连山
我国西北干旱区内高山环列，形成了高山与盆 地相间的地貌格局. 正是由于这些高大山系的存在, 促使了冰川的发育, 并截获了大气中较多的水汽使 山区的降水量明显高于山前荒漠地带, 使其成为我 国西北干旱区中的“湿岛”. 高山冰雪融水与降水是 内陆河的重要水源, 它们不仅维系着中下游人工绿 洲的发展和自然绿洲的存在, 而且也是下游沙漠地 区众多终闾湖泊与环境演化的主要影响因素. 深入 开展我国西北内陆河流域水资源的形成与转化以及 水的循环过程与机理研究, 将是该地区水资源合理 利用与生态环境建设的重要科学基础. 同位素方法 在示踪水资源形成、循环与转化过程方面已经得到了 广泛的应用 ${ }^{[1-9]}$. 目前, 在黑河流域也开展了这一方 面的相关研究工作 ${ }^{[10 \sim 14]}$, 并对该流域山前绿洲地区及 下游地区的地表水与地下水转化取得了一些定量认识 [10,14]. 然而, 对黑河上游祁连山区地表径流水资源在 不同高度带的形成状况还缺乏系统的观测与研究, 本 文试图从同位素示踪角度开展这一方面的研究.

\section{1 研究区自然地理概况}

黑河流域跨越青海、甘肃和内蒙古三省/自治区,
地理位置大致介于 $96^{\circ} 42^{\prime} \sim 102^{\circ} 04^{\prime} \mathrm{E}, 37^{\circ} 45^{\prime} \sim 42^{\circ} 40^{\prime} \mathrm{N}$ 之 间, 流域面积 $13 \times 10^{4} \mathrm{~km}^{2}$, 是我国西北干旱区第二大内 陆河流域. 黑河流域地貌特征区域差异显著, 南部为祁 连山山地, 中部为走廊平原, 北部为低山山地和阿拉善 高原, 并与巴丹吉林沙漠接壤. 上游祁连山区景观垂直 地带性也十分明显, 从山前到高山区依次为荒漠草原 带、干性灌丛草原带、山地森林草原带、亚高山灌丛草 甸带、高山寒漠草甸带 ${ }^{[15]}$ 和高山冰雪带.

通过对气象站观测资料的分析表明 ${ }^{[16]}$, 黑河上游祁 连山区降水量从东向西呈减少趋势, 并随海拔升高而增 加, 年降水量在低山区为 $200 \mathrm{~mm}$ 左右, 而在高山区可达 $600 \mathrm{~mm}$ 左右, 降水主要集中在夏季. 根据冰川编目资料 [17], 黑河流域(包括北大河流域)共有冰川 1078 条, 面积 为 $420.55 \mathrm{~km}^{2}$, 冰储量为 $13.67 \mathrm{~km}^{3}$ (约合计 $123.03 \times 10^{8}$ $\mathrm{m}^{3}$ 水当量). 黑河干流出山口莺落峡水文站控制流域总 面积为 $10009 \mathrm{~km}^{2}$, 高程范围在海拔 $1674 \sim 5103 \mathrm{~m}$ 之间 (平均海拔高度为 $3737.7 \mathrm{~m}$ ), 流域内有冰川 219 条, 面积 为 $59 \mathrm{k} \mathrm{m}^{2}$, 冰储量为 $1.38 \mathrm{k} \mathrm{m}^{3}$ (约合计 $12.43 \times 10^{8} \mathrm{~m}^{3}$ 水当量).八一冰川是黑河干流流域最大的 冰川, 长度为 $2.2 \mathrm{~km}$, 面积为 $2.81 \mathrm{~km}^{2}$. 黑河流域有大小 
河流 41 条, 多年平均年出山径流总量约为 $36.8 \times 10^{8}$ $\mathrm{m}^{3}$, 其中黑河干流的年出山径流量最大, 约为 $16.0 \times 10^{8} \mathrm{~m}^{3[18]}$.

\section{2 资料与方法}

2006 年 4 月至 2007 年 5 月, 我们在黑河干流出 山口茑落峡水文站、上游东支八宝河祁连水文站、上 游西支扎麻什河扎麻什水文站进行了河水样品的逐 日定时(每日 20:00 时)采集. 每次河水样品采集时, 先装入 $100 \mathrm{~mL}$ 塑料瓶内, 然后再用蜡密封其瓶盖封 口. 另外, 在临泽(海拔 $1367 \mathrm{~m}$ )、莺落峡(海拔 1674 $\mathrm{m}) 、$ 祁连(海拔 $2787 \mathrm{~m}$ )、扎麻什(海拔 $2835 \mathrm{~m}$ ) 和野牛 沟(海拔 $3320 \mathrm{~m}$ )等站点采集了降水样品. 每次降水样 品采集时, 同时记录了该次降水的降水量以及降水 开始和结束时的气温. 降水样品也是在装入 $100 \mathrm{~mL}$ 塑料瓶后, 再用蜡密封其瓶盖封口. 2006 年野外考察 期间, 我们还在黑河干流源区八一冰川海拔 4650 4800 m 冰面上采集了冰雪样品, 以获得高海 拔处降水中的稳定同位素比率值. 本文涉及的采样 地点位置见图 1. 采集到的所有样品均在冰冻圈科学 国家重点实验室分析完成, 分析所用的仪器是气体 稳定同位素比质谱仪(MAT-252), 其样品中 $\delta^{18} \mathrm{O}$ 的分 析精度为 $\pm 0.05 \%$ 。

图 2 是黑河出山口茑落峡水文站河水中 $\delta^{18} \mathrm{O}$ 月平 均值变化情况, 其值变化于-7.48\%o - $8.11 \%$ 之间, 年 平均值为 $-7.78 \%$. 图 3 是研究区域各站点降水中 $\delta^{18} \mathrm{O}$ 的降水量加权平均值变化情况, 从图中可以看出它 们的季节变化特征极为显著(夏季高冬季低), 并且低 海拔站点降水中 $\delta^{18} \mathrm{O}$ 比高海拔站点的高(即高程效应). 对比图 2 和 3, 可以看出黑河出山口河水中 $\delta^{18} \mathrm{O}$ 季节 变化不仅幅度较小, 而且滞后于其上游祁连山山区 降水中 $\delta^{18} \mathrm{O}$ 的季节变化, 这主要反映了降水下渗导致 的壤中流及地下水汇流过程较缓慢以及出山口上游 方向水库夏季蓄水调节的影响. 对苞落峡水文站、祁 连水文站、扎麻什水文站河水样品中 $\delta^{18} \mathrm{O}$ 分析结果的 研究表明 ${ }^{[19]}$, 在黑河上游中低山地区干流河水中 $\delta^{18} \mathrm{O}$ 沿程变化不大. 这说明黑河上游山区河段河水沿 程蒸发很少, 对河水中 $\delta^{18} \mathrm{O}$ 的影响较小. 观测表明, 2006 年黑河干流流域的冰川融水径流为 $0.66 \times 10^{8} \mathrm{~m}^{3}$, 仅占该年出山径流 $\left(18.1 \times 10^{8} \mathrm{~m}^{3}\right)$ 的 $3.6 \%$ [20]. 这说明 黑河干流径流的形成主要受降水的影响. 其他地区 的大量研究表明，在许多大河的源区

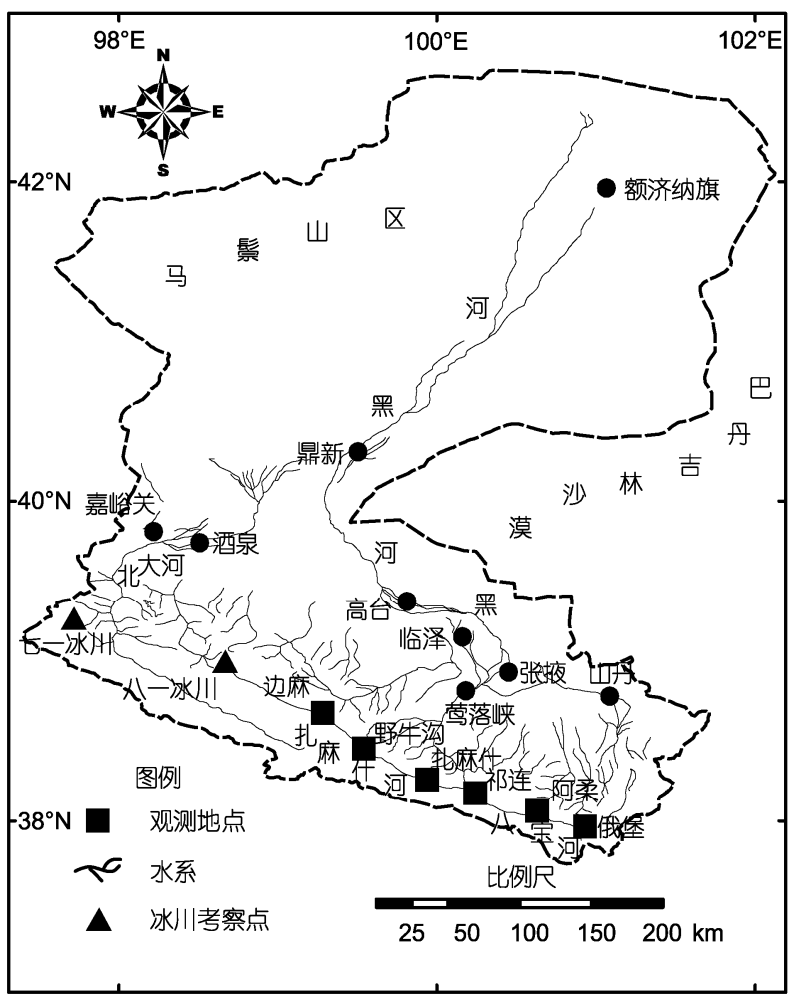

图 1 黑河流域河水与降水样品采集地点及考察地点位置

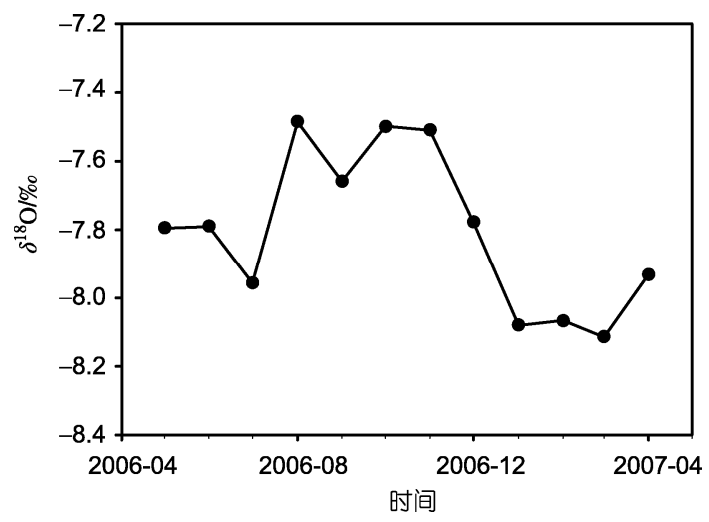

图 22006 年 5 月至 2007 年 4 月黑河莺落峡水文站河水 中 $\delta^{18} \mathrm{O}$ 月平均值变化

其河水中稳定同位素比率非常接近其地方降水中稳 定性同位素比率 ${ }^{[21 ~ 23]}$, 而且在许多小流域的地表与 地下水体中稳定同位素比率接近地方降水中稳定同 位素比率的年平均值 ${ }^{[24]}$. 鉴于此, 我们可以利用降水 中 $\delta^{18} \mathrm{O}$ (以降水量加权的年平均值为基础, 以消除降 水下渗导致的壤中流及地下水汇流过程的影响)的高 程效应, 并结合黑河干流出山口河水中 $\delta^{18} \mathrm{O}$ 的年平均 值, 根据物质守恒定律来判断出山径流形成的主要 高程区域. 


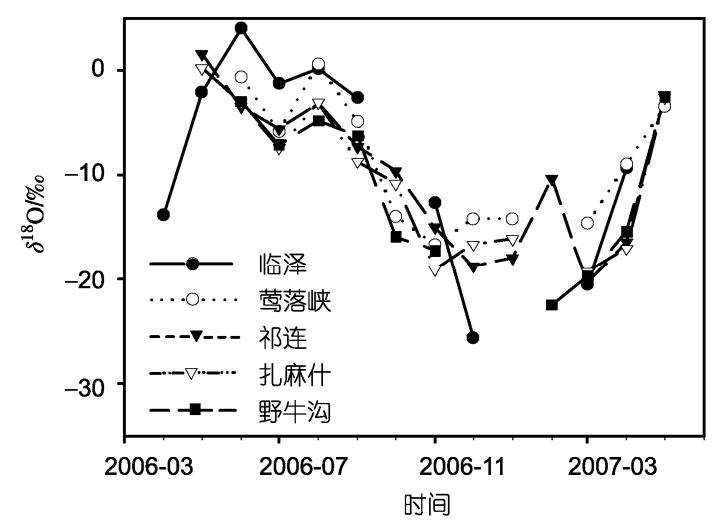

图 32006 年 4 月至 2007 年 5 月黑河流域不同地点降水 中 $\delta^{18} \mathrm{O}$ 降水量加权平均值逐月变化

黑河流域气象站位置均位于海拔 $3500 \mathrm{~m}$ 以下, 即低于其上游山区的平均高程. 由于山区降水量的 空间变化差异较大, 为了估算不同高程带的降水量 状况, 必须对高海拔处的降水状况进行观测. 自 2006 年夏季以来我们在黑河流域上游山区的俄堡、阿柔、 祁连、扎麻什、野牛沟和边麻等 6 个地点以及七一冰 川流域开展了不同海拔高度降水量的观测(地点位置 见图 1), 并获得了较系统的降水量资料 ${ }^{[25]}$.

\section{3 结果与讨论}

图 4 是 2006 年 5 月至 2007 年 5 月黑河流域降水 中 $\delta^{18} \mathrm{O}$ 降水量加权平均值随海拔高度的变化情况. 从该图可以看出, 在黑河中上游地区降水中 $\delta^{18} \mathrm{O}$ 随 海拔高度 $(H)$ 的升高而降低(即高程效应), 其线性关 系为

$$
\delta^{18} \mathrm{O}=-0.001769 H-1.02,\left(R^{2}=0.886, n=6\right) .
$$

式(1)表明, 黑河流域降水中 $\delta^{18} \mathrm{O}$ 的高度梯度约为 $-0.18 \% / 100 \mathrm{~m}$. 该梯度值位于全球不同地区降水中 $\delta^{18} \mathrm{O}$ 的高度梯度值的变化范围 (大致变化于-0.10 $\left.-0.50 \% / 100 \mathrm{~m}^{[2]}\right)$ 之内. 由于黑河干流出山径流主要 来自降水的影响, 那么根据这里黑河上游降水中 $\delta^{18} \mathrm{O}$ 随海拔高度的变化规律以及黑河干流出山口莺落峡 水文站河水中 $\delta^{18} \mathrm{O}$ 年平均值 $(-7.78 \%$, 这一数值是 2006 年 5 月至 2007 年 5 月茑落峡水文站逐日河流样 品中 $\delta^{18} \mathrm{O}$ 的算术平均值. 我们曾采用流量加权平均值 法和简单算术平均值法对祁连水文站河水中 $\delta^{18} \mathrm{O}$ 年 平均值进行了计算, 两种算法所得结果的差异仅为 $0.09 \%$ ․ 19$]$. 由于缺乏莺落峡水文站逐日流量资料, 加 之河水中 $\delta^{18} \mathrm{O}$ 季节变化幅度很小，所以本文采用
的苞落峡水文站河水中 $\delta^{18} \mathrm{O}$ 年算术平均值所做的相 关计算将不会引起大的误差)，初步估计黑河干流径 流主要形成在海拔 $3820 \mathrm{~m}$ 左右的高度带地区. 该高 度带附近的山地面积占流域面积的比例也相对较大 (见图 5, 高度-面积分布资料取自文献[26]).

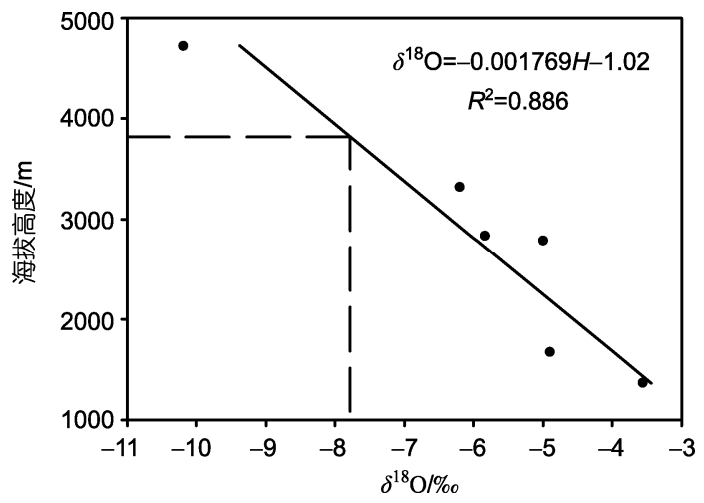

图 42006 年 5 月至 2007 年 5 月黑河流域降水中 $\delta^{18} O$ 降 水量加权平均值随海拔高度的变化

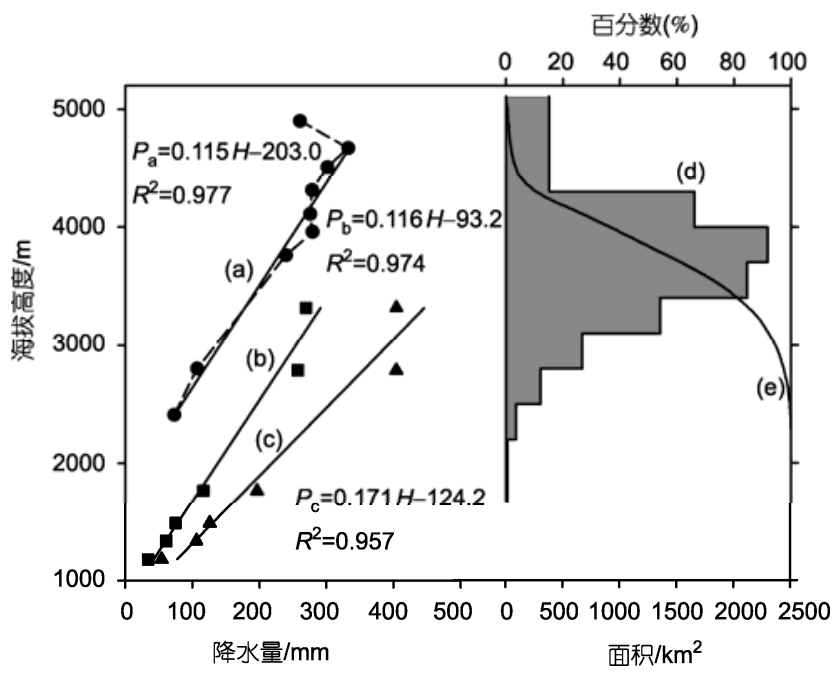

图 5 黑河流域降水量以及不同高度带面积随海拔 升高的变化情况

(a) 七一冰川流域 2008 年 5 月 22 日至 9 月 12 日降水量 $\left(P_{\mathrm{a}}\right)$; (b) 黑 河流域气象站多年平均夏季降水量 $\left(P_{\mathrm{b}}, 1960 \sim 2004\right.$ 年); (c) 黑河流 域气象站多年平均年降水量 $\left(P_{\mathrm{c}}, 1960 \sim 2004\right.$ 年); (d) 不同高度带面 积; (e) 不同高度带面积百分率累积值

揭示降水量随海拔的变化情况, 是认识山区不 同海拔高度带降水径流量的重要基础. 根据鼎新、高 台、张掖、山丹、祁连和野牛沟气象站的长期观测资 料, 发现黑河流域在海拔 $3500 \mathrm{~m}$ 以下的中低山区不 论是年降水量 $\left(P_{\mathrm{c}}\right)$ 还是夏季降水量 $\left(P_{\mathrm{b}}\right)$ 均随海拔高度 $(H)$ 的升高而增大(图 5(b), (c)), 并且年降水量随海拔 
升高的递增率为 $17.1 \mathrm{~mm} / 100 \mathrm{~m}$, 夏季降水量随海拔 升高的递增率为 $11.6 \mathrm{~mm} / 100 \mathrm{~m} .2008$ 年夏季, 我们 在七一冰川流域进行的降水量观测(图 5(a)), 弥补了 研究区域高山带降水量随海拔变化的资料. 结果表 明, 在海拔 $4670 \mathrm{~m}$ 左右存在一个最大降水高度带, 该高度以下降水量随海拔升高而增加, 在该高度带 以上(山地面积很少, 见图 5(e))降水量随海拔升高而 减小. 如果我们对最大降水高度以下降水量随海拔 高度的变化(图 5(a)) 用一个线性来拟合, 那么 2008 年 5 月 22 日至 2008 年 9 月 12 日时段降水量 $\left(P_{\mathrm{a}}\right.$, 夏季 降水量)随海拔升高的递增率为 $11.5 \mathrm{~mm} / 100 \mathrm{~m}$. 这与 黑河干流海拔 $3500 \mathrm{~m}$ 以下中低山区夏季降水量随海 拔升高的递增率 $(11.6 \mathrm{~mm} / 100 \mathrm{~m})$ 极为一致, 说明我 们可以利用黑河干流中低山地区年降水量及其随高 度变化的梯度值, 来进行高山地区年降水量的推算. 值得注意的是, 在同高度上七一冰川流域夏季降水 量比黑河干流流域的偏小(图 5(a), (b)), 这是祁连山 区降水量从东向西减少的表现. 如果利用观测到的 黑河流域中山带以下夏季降水量随海拔的递增率, 将 2006 年夏季我们在黑河上游山区 6 个观测点(俄 堡、阿柔、祁连、扎麻什、野牛沟和边麻, 见图 1) 的降水量订正到海拔 $3000 \mathrm{~m}$ 的同一个高度上(图 6), 可以估计出 2006 年夏季黑河上游山区降水量从东向 西的递减率约为 $80 \mathrm{~mm} / 100 \mathrm{~km}$ 左右. 从图 1 可以看 到, 张掖-祁连-扎麻什一线大致垂直于黑河干流上游 山区东西方向的中部, 而且祁连-扎麻什一带订正到 海拔 $3000 \mathrm{~m}$ 高度的夏季降水量为 $280.0 \mathrm{~mm}$ 左右, 接 近该高度带东西方向夏季降水量的平均值 $277.3 \mathrm{~mm}$. 因此, 可以选择这一线的年降水量随高度变化状况 来代表黑河干流流域的平均状况. 为了计算时间的 统一性, 本文具体计算时应用 2006 年张掖-祁连一线 降水量 $(P)$ 与海拔高度 $(H)$ 之间的关系式:

$$
P=0.1833 H-148.4,\left(R^{2}=0.950, n=6\right) .
$$

最近对黑河上游山区植被的空间分布特征研究 表明, 植被指数随海拔高度的增加逐渐增大, 在海拔 $3400 \mathrm{~m}$ 处达到峰值, 植被发育最好, 而后随着海拔高 度的增加逐渐减小 ${ }^{[27]}$. 考虑到不同植被带的产流情 况不同, 以及黑河上游山区多年冻土下界在海拔 $3600 \mathrm{~m}$ 左右 ${ }^{[28]}$ 和黑河干流径流主要形成在海拔 $3820 \mathrm{~m}$ 左右的高度带, 我们将黑河干流山区流域以海拔 $3600 \mathrm{~m}$ 为界分为上下两部分, 上部为高山冰雪冻土 带, 下部为中低山植被带(康尔泗等人 ${ }^{[26]}$ 曾经也这样

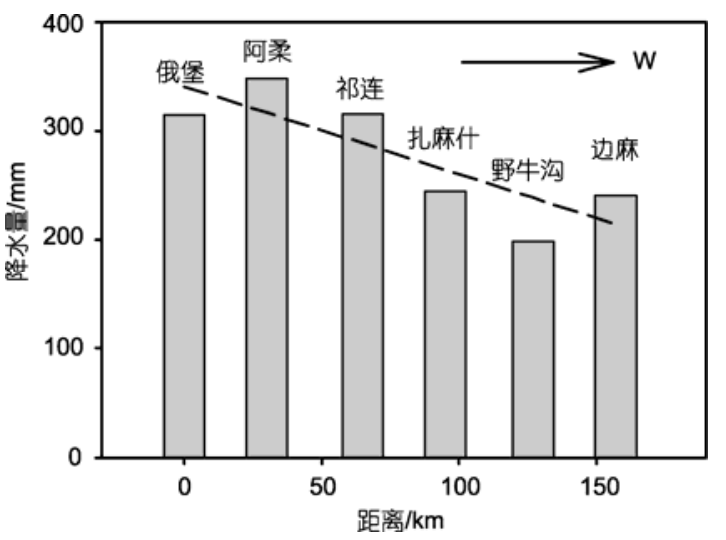

图 62006 年夏季黑河上游山区海拔 $3000 \mathrm{~m}$ 高度处降水 量(订正值)从东到西变化

划分黑河上游流域). 根据公式(1)和图 5 中不同高度 带面积分布状况, 可求出高山冰雪冻土带降水中 $\delta^{18} \mathrm{O}$ 的降水量-面积加权平均值 $\left(\delta^{18} \mathrm{O}_{\text {上 }}\right)$ 为 $-8.05 \%$, 中低山 植被带降水中 $\delta^{18} \mathrm{O}$ 的降水量 - 面积加权平均值 $\left(\delta^{18} \mathrm{O}_{\mathrm{F}}\right)$ 为 $-6.69 \%$. 设高山冰雪冻土带产流量为 $Q$ 上, 中低山 植被带产流量为 $Q$ 下, 根据物质守恒有

$$
\begin{gathered}
Q_{\text {总 }} \cdot \delta^{18} \mathrm{O}=Q_{\text {上 }} \cdot \delta^{18} \mathrm{O}_{\text {上 }}+Q_{\text {下 }} \cdot \delta^{18} \mathrm{O}_{\text {下 }}, \\
Q_{\text {总 }}=Q_{\text {上 }}+Q_{\text {下 }},
\end{gathered}
$$

式中 $Q$ 总为出山径流量, $\delta^{18} \mathrm{O}$ 总为出山口河水中的年平均 $\delta^{8} \mathrm{O}(-7.78 \%$ ) . 式(3)，(4)就是同位素示踪研究中常用的 “二分量模型” [3]. 将 2006 年的相关参数值代入上述两 公式, 联立求解, 得到 $Q_{上}=14.52 \times 10^{8} \mathrm{~m}^{3}, Q_{\text {下 }}=3.58 \times 10^{8}$ $\mathrm{m}^{3}$. 这表明高山冰雪冻土带(即海拔 $3600 \mathrm{~m}$ 以上流域范 围, 其面积占出山口以上流域面积的 58.9\%)是黑河干流 流域的主要产流区, 该区域产流量占出山径流量的 $80.2 \%$ (如果考虑到蒸发过程对汇入河道的水中 $\delta^{18} \mathrm{O}$ 的影 响, 这里关于高山冰雪冻土带产流量的估计值是最小估 计, 因为蒸发量随海拔升高而减小, 这使得低海拔处汇 入河道的水中 $\delta^{18} \mathrm{O}$ 更偏大一些), 而中低山植被带产流量 仅占出山径流量的 $19.8 \%$. 康尔泗等人 ${ }^{[29]}$ 最近根据降水 量、蒸散发量随海拔升高的对比关系, 研究了黑河干流 山区流域的产流情况, 也认为高山冰雪冻土带是主要产 流区, 产流量为出山径流量的 $83 \%$. 由此可见, 不同方 法的研究结果是比较一致的. 根据上述计算结果, 我们 还可以计算出 2006 年黑河干流上游高山冰雪冻土带的 径流深为 $246.4 \mathrm{~mm}$, 中低山植被带的径流深为 $86.9 \mathrm{~mm}$, 上游山区的平均径流深为 $180.8 \mathrm{~mm}$. 另外, 根据公式(2) 和图 5 中不同高度带(小带)面积分布状况, 求得 
2006 年黑河上游山区平均降水量为 $521.6 \mathrm{~mm}$, 高山 冰雪冻土带平均降水量为 $579.6 \mathrm{~mm}$, 中低山植被带 平均降水量为 $438.6 \mathrm{~mm}$. 依据这些资料, 可得到黑 河干流上游山区的径流系数为 0.347 , 高山冰雪冻土 带的径流系数为 0.425 , 中低山植被带的径流系数为 0.198. 通过以上分析, 我们认为高海拔处的高降水 量、低蒸散发量和高径流系数, 使得这一高度带地区 成为黑河地表径流的主要产流区.

\section{4 结论}

同位素水文学研究已成为水文学研究的一个重要 前沿领域. 研究各种水体中稳定同位素的时空变化特
征及其影响因素，是利用稳定同位素技术开展水文过 程、水文循环与水资源转化等研究的重要基础. 本文 通过对黑河干流流域降水中 $\delta^{18} \mathrm{O}$ 的研究, 揭示出其变 化具有显著的高程效应. 根据这种特征以及出山口河 水中 $\delta^{18} \mathrm{O}$ 值与降水量高程分布，利用“二分量模型”, 揭示出海拔 $3600 \mathrm{~m}$ 以上的高山冰雪冻土带是黑河山 区流域的主要产流区, 该区域的径流系数为 0.425 , 这 明显地高于我国西北干旱内流区的平均径流系数值 $\left(0.165^{[30]}\right)$. 该结果表明, 干旱区高山地带的气候与气 候变化对山区径流水资源的形成与演化具有重要影 响，这是值得进一步深入开展研究的课题.

\section{参考文献}

1 Agency International Atomic Energy. Tritium and Other Environmental Isotopes in the Hydrological Cycle. Vienna: International Atomic Energy Agency, 1967. 1-83

2 Clark I D, Fritz P. Environmental Isotopes in Hydrogeology. New York: Lewis Publishers, 1997. 35-78

3 Kendall C, Mcdonnell J J. Isotope Tracers in Catchment Hydrology. Amsterdam: Elsevier, 1998. 723-760

4 Taniguchi M, Nakayama T, Tase N, et al. Stable isotope studies of precipitation and river water in the Lake Biwa Basin, Japan. Hydrol Proc, 2000, 14: 539-556[doi]

5 Gibson J J, Edwards T W D, Birks S J, et al. Progress in isotope tracer hydrology in Canada. Hydrol Proc, 2005, 19: 303-327[doi]

6 Lambs L, Balakrishna K, Brunet F, et al. Oxygen and hydrogen isotopic composition of major Indian rivers: A first global assessment. Hydrol Proc, 2005, 19: 3345-3355[doi]

7 Kattan Z. Estimation of evaporation and irrigation return flow in arid zones using stable isotope ratios and chloride mass-balance analysis: Case of the Euphrates River, Syria. J Arid Environ, 2008, 72: 730-747 [doi]

8 刘丹, 刘世青, 徐则民. 应用环境同位素方法研究塔里木河下游浅层地下水. 成都理工学院学报, 1997, 24: 89一95

9 宋献方, 刘相超, 夏军, 等. 基于环境同位素技术的怀沙河流域地表水和地下水转化关系研究. 中国科学 D辑: 地球科学, 2007, 37: $102-110$

10 张应华，仵彦卿，丁建强，等. 运用氧稳定同位素研究黑河中游盆地地下水与河水转化. 冰川冻土, 2005, 27: 106一 110

11 聂振龙，陈宗宇，申建梅，等。应用环境同位素方法研究黑河源区水文循环特征. 地理与地理信息科学, 2005, 21: 104一108

12 张光辉，聂振龙，谢悦波，等。甘肃西部平原区地下水同位素特征及更新性. 地质通报, 2005, 24: 149-155

13 张光辉, 聂振龙, 王金哲, 等。黑河流域水循环过程中地下水同位素特征及补给效应. 地球科学进展, 2005, 20: 511一 519

14 陈宗宇，万力，聂振龙，等. 利用稳定同位素识别黑河流域地下水的补给来源. 水文地质工程地质，2006，6:9一14

15 王金叶, 常学向, 葛双兰, 等. 祁连山(北坡)水热状况与植被垂直分布. 西北林学院学报, 2001, 16(增刊): 1一 3

16 丁永建，叶佰生，周文娟. 黑河流域过去 $40 \mathrm{a}$ 来降水时空分布特征. 冰川冻土, 1999, 21: 42-48

17 王宗太, 刘潮海, 尤根祥, 等。中国冰川目录(I)祁连山区。兰州: 中国科学院兰州冰川冻土研究所, 1981

18 肖洪浪. 中国水情. 北京: 开明出版社, 2000. 179-180

19 王宁练，张世彪，蒲建辰，等. 黑河上游河水中 $\delta^{18} \mathrm{O}$ 的季节变化特征及其影响因素研究. 冰川冻土, 2008, 30: 914 - 920

20 贺建桥，宋高举，蒋喜，等. 2006 年黑河水系典型流域冰川融水径流与出山径流的关系。中国沙漠, 2008, 28: 1186一1189

21 Frederickson G C, Criss R E. Isotope hydrology and time constants of the unimpounded Meramec river basin, Missouri. Chem Geol, 1999, 157: 303-317[doi]

22 Kendall C, Coplen T B. Distribution of oxygen-18 and deuterium in river waters across the United States. Hydrol Proc, 2001, 15: 1363 - 1393 [doi]

23 Winston W E, Criss R E. Oxygen isotope and geochemical variations in the Missouri River. Environ Geol, 2003, 43: 546-556

24 Frits P. River waters. In: Stable Isotope Hydrology, Deuterium and Oxygen-18 in the Water Cycle. Tech Rep Ser No. 210, IAEA. Vienna: International Atomic Energy Agency, 1981

25 王宁练, 贺建桥, 蒋喜, 等. 祁连山中段北坡最大降水高度带观测与研究. 冰川冻土, 2009, 31: 395-403

26 康尔泗，程国栋，董增川。中国西北千旱区冰雪水资源与出山径流. 北京: 科学出版社, 2002. 248-304

27 金晓媚，万力，胡光成．黑河上游山区植被的空间分布特征及其影响因素. 千旱区资源与环境, 2008, 22: 140一144

28 周幼吾，郭东信，邱国庆，等。中国冻土。北京：科学出版社, 2000. 309-326

29 康尔泗，陈仁升，张智慧，等.内陆河流域山区水文与生态研究. 地球科学进展, 2008, 23: 675-681

30 中国科学院《中国自然地理》编辑委员会. 中国自然地理(地表水). 北京: 科学出版社, 1981. 12-15 